\title{
Determinação de Parâmetros Otimizados na Soldagem a Ponto por Resistência Utilizando Duas e Três Chapas em uma Indústria Automobilística
}

\author{
Kennedy R. Rosario, João C. R. Costa, Sérgio M. Brandão, Márcio J. \\ Dias, Rosemberg F. N. Rodrigues \& Wilson P. Silva
}

Os parâmetros utilizados no processo de soldagem são fatores determinantes para obtenção de soldas com qualidade, sendo assim, o presente trabalho teve como objetivo a determinação de parâmetros otimizados para o processo de RSW (resistance spot welding) com duas e três chapas, utilizadas em uma indústria automobilística. Baseando-se nos três principais parâmetros da soldagem a ponto, corrente, força e tempo, o estudo foi dividido em 3 etapas, para cada mix de chapas, realizando a análise individual da influência de cada um dos parâmetros. Através de ensaios de tração foram obtidos valores de força máxima e diâmetro médio das lentilhas, sendo determinados parâmetros otimizados para o processo de soldagem, tendo os valores para a soldagem de duas chapas corrente de $8,0 \mathrm{kA}$, pressão de $2,5 \mathrm{kN}$ e tempo de $250 \mathrm{~ms}$, e para três chapas corrente de $8,5 \mathrm{kA}$, pressão de $3 \mathrm{kN}$ e tempo de $250 \mathrm{~ms}$.

Palavras-chave: soldagem a ponto; parâmetros; resistência a tração.

The parameters used in the welding process are determining factors for obtaining quality welds, so this study aimed to determine parameters optimized for the RSW process (resistance welding point) with two and three sheets, used in an auto industry. Based on the three parameters of spot welding, current, force and time, the study is divided into 3 stages, for each mix of sheets, performing an individual analysis of the influence of each of the parameters. Through tensile tests the values of maximum force and average diameter of the lentils were obtained, being determined parameters optimized for the welding process, having the values for the welding of two sheets current of $8.0 \mathrm{kA}$, pressure of $2.5 \mathrm{kN}$ and time $250 \mathrm{~ms}$, and for three plates current of $8.5 \mathrm{kA}$, pressure of $3 \mathrm{kN}$ and time of $250 \mathrm{~ms}$.

Keywords: spot welding; parameters; tensile strength. 


\section{Introdução}

Este estudo surge da necessidade de capabilidade do processo de soldagem por resistência em indústrias automotivas, onde grandes volumes de pontos de solda são realizados em um curto período de tempo, o que limita a checagem dos pontos realizados com inspeções visuais e esporadicamente testes de destacamento, fazendo com que a parametrização correta das máquinas de solda seja um item de extrema importância para garantia da qualidade do processo. Na confecção da carroceria de um automóvel são dados cerca de 4500 mil pontos de solda, sendo o processo de soldagem por resistência o mais utilizado por apresentar qualidade e resistência satisfatórias, feitos por sistemas robóticos ou manuais. A RSW (Resistance spot welding) trata-se da união de chapas metálicas sobrepostas ou em contato topo a topo através de uma solda formando um ponto de fusão (lentilha de solda), devido ao calor gerado pela resistência do material à passagem de corrente elétrica (efeito joule) com a devida pressão dos eletrodos ${ }^{1,2}$.

Segundo Emílio Wainer a energia térmica total gerada durante o processo de soldagem depende das resistências do conjunto, passagem e duração da corrente, podendo ser calculada pela lei de Joule, conforme a Equação 1.

$$
Q=I^{2} \cdot R \cdot T
$$

Em que: $Q=$ Calor gerado (joules); $I=$ Intensidade da corrente (amperes); $R=$ Resistência elétrica $(\mathrm{Ohms}) ; T=$ Tempo de passagem da corrente (segundos).

Os valores da Intensidade da corrente (I), assim como do tempo de passagem dessa $(T)$ podem ser alterados pelos ajustes dos controles de solda, enquanto a resistência das peças que estão sendo soldadas é mantida fixa. Todas as resistências elétricas do circuito secundário são relevantes ao processo, devido aos elevados valores de correntes de soldagem, sendo a resistência total $(R T)$ obtida pela soma das parciais, conforme a Equação $2^{3}$ :

$$
R T=R 1+R 2+R 3+R 4+R 5
$$

Em que: $R 1=$ Resistência de contato entre eletrodo superior e peça superior; $R 2$ = Resistência da peça superior; $R 3$ = Resistência de contato entre peça superior e peça inferior; $R 4=$ Resistência da peça inferior; $R 5=$ Resistência de contato entre eletrodo superior e peça inferior.

Como mostrado na Figura 1 o ponto R3 representa a região na qual se tem a maior resistência do circuito entre peça superior e peça inferior é também onde se tem o maior aquecimento, realizando a fundição de maneira contínua até formar a lentilha de solda. Sendo o ponto de resistência mais significativo após o contato entre as peças, o contato entre eletrodo e peça sofre grande aquecimento, mas sem atingir seu ponto de fusão, pois durante o processo sofre rápida refrigeração devido ao resfriamento dos eletrodos que geralmente é feito com água ${ }^{2}$.

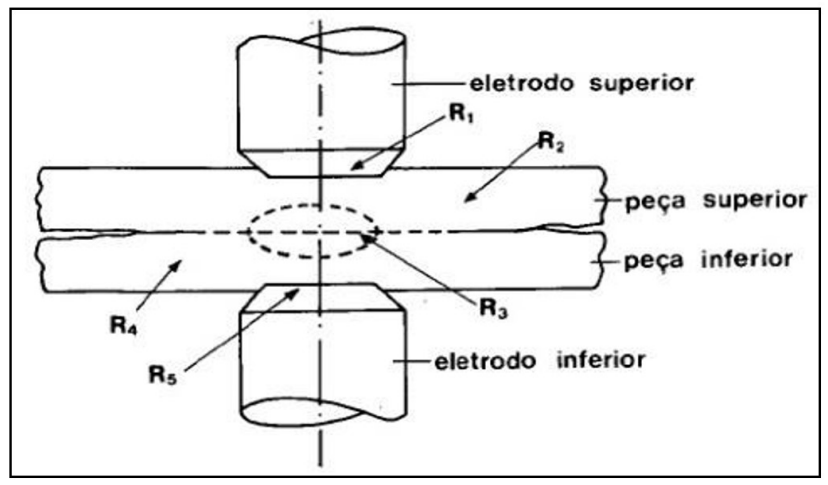

Figura 1. Resistencia elétrica de contato. Fonte: referência [3].

Conforme se observa na Figura 2, as regiões de 2 a 6 são os locais que sofreram transformações metalúrgicas. E representada pela região 1 , a área da peça que não foi termicamente afetada pelo calor gerado durante a soldagem ${ }^{3}$. Sendo os processos de soldagens sujeitos a variabilidades, suas variações podem ser provenientes da matéria-prima, 
máquinas e equipamento, métodos de trabalho, condições ambientais e a mão de obra envolvida, mas ainda assim devem possuir rigorosos valores dimensionais para dar condição aos processos seguintes.

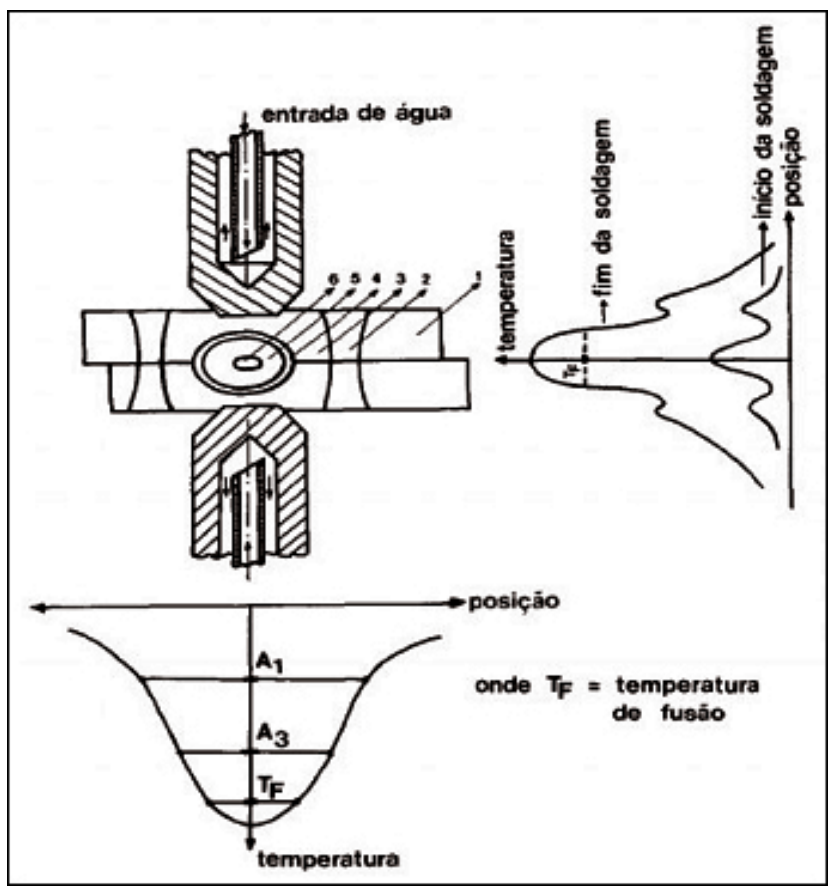

Figura 2: Distribuição da temperatura em uma soldagem por ponto. Fonte: referência [3].

\section{PARÂMETROS}

A formação da lentilha de solda está diretamente ligada a parâmetros, como: corrente, pressão e tempo de soldagem, controlando a quantidade de calor gerada na transformação de energia elétrica em térmica. A correta combinação desses define boa qualidade de solda obtendo uma resistência mecânica proporcional à seção de corte das peças fundidas, caso contrário apresentará baixa resistência e diversos defeitos ${ }^{4,5}$.

\section{CORRENTE DE SOLDAGEM}

A corrente é a variável que mais possui influência sobre a soldagem, em que possui um limite inferior e superior no qual, se seus valores aplicados não forem altos o suficiente para a fusão do material não ocorrerá a formação da lentilha, assim como se excedidos podem gerar a expulsão de material e uma excessiva penetração dos eletrodos nas chapas, reduzindo a vida útil do eletrodo e produzindo soldas com baixa qualidade. Seu valor deve ser ajustado para compensar as perdas por condução durante a soldagem, com valor de corrente utilizado logo abaixo do valor no qual ocorre a expulsão de material fundido ${ }^{5,6}$.

A corrente de soldagem pode variar sua densidade na face da junta a ser soldada com relação ao diâmetro de face do eletrodo utilizado, podendo aumentar quando se tem um aumento do diâmetro do eletrodo reduzindo o calor gerado na junta da solda, assim como a redução do diâmetro do eletrodo gera um aumento da densidade da corrente podendo gerar expulsão de material ocasionando possíveis vazios internos rebarbas ou excessivas indentações?

\section{PRESSÃO DE SOLDAGEM}

As superfícies dos materiais a serem soldados apresentam defeitos e impurezas que impedem o contato total entre o metal-metal, como: rugos idade; óxidos; umidade; gordura; poeira; etc., portanto diminuem a área de contato que consequentemente aumenta a densidade da corrente na região a ser soldada, assim para melhorar o assentamento dos materiais são aplicadas as forças dos eletrodos. As forças dos eletrodos estão relacionadas as etapas do ciclo da solda, sendo responsáveis por fixar e aproximar as peças reduzindo as possíveis folgas entre chapa-chapa e chapa-eletrodo, assim como forjar os metais quando eles se encontram no estado plástico. A pressão de soldagem tem como uma das funções refinar a estrutura dos grãos tornando as propriedades físicas do ponto de solda iguais ou até mesmo superiores às do metal deorigem. ${ }^{5,6}$.

\section{TEMPO DE SOLDAGEM}

É a duração do fornecimento da corrente de soldagem, que determina o calor total para realização do ponto de solda. $\mathrm{Na}$ grande maioria sendo tempos muito curtos para evitar a perda de calor por condução, uma vez que as perdas de calor aumentam conforme seja aumentado o tempo de soldagem, 
tornando-se necessários elevados valores de correntes para atingir o calor para a fusão dos materiais ${ }^{6-8}$.

\section{CICLO DE SOLDAGEM.}

O ciclo de soldagem se inicia pelo tempo de compressão que é finalizado quando se incia a passagem da ocorre, sendo dividido em duas etapas: tempo de fechamento dos eletrodos (acostamento) e tempo de pré-pressão, indicados na Figura 3 por (a) e (b) respectivamente. O tempo de compressão deve ser longo o suficiente para a aproximação dos eletrodos sem que haja um impacto muito grande e para que a força dos eletrodos se estabilize nos valores determinados. Sendo imprescindível uma correta sincronização entre o início da soldagem e o tempo de compressão, pois se o tempo de prépressão for muito curto pode levar a grandes expulsões de materiais das regiões fundidas, assim como tempo longo pode aumentar significativamente o custo da produção devido ao tempo excessivo do ciclo de soldagem ${ }^{6}$.

O tempo de soldagem é o tempo de aplicação da corrente de soldagem para gerar a fusão e deformação dos materiais, indicando na Figura 3 como ponto (c), seguido do tempo de resfriamento, também denominado de pós-pressão, em que as pinças mantem a pressão após a passagem da corrente elétrica para que a lentilha de solda possa se resfriar e solidificar até sua adequada resistência mecânica, evitando rompimento e deformações da região soldada, mostrado pelo ponto $(\mathrm{d})^{9}$.

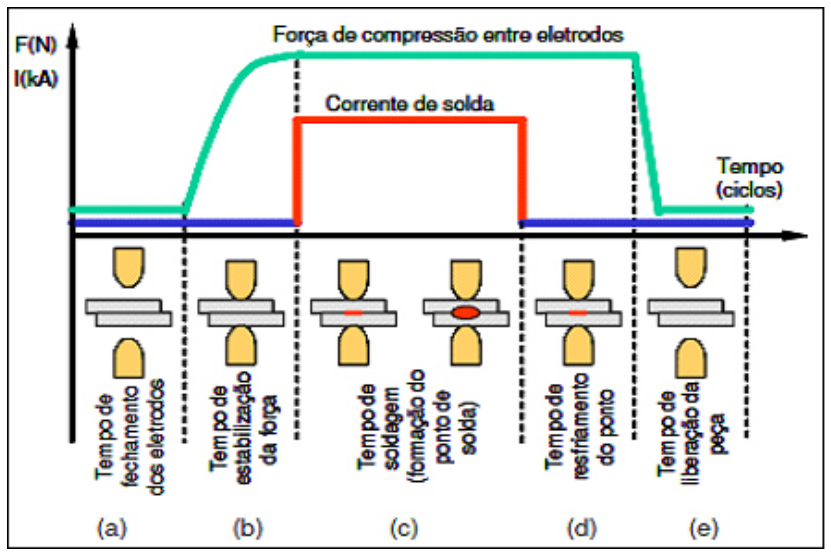

Figura 3: Ciclos da soldagem. Fonte: referência [7].

\section{DEFEITOS}

Os defeitos de soldagem presentes em linhas de produção são considerados itens graves, em que muitas vezes são controlados diariamente a fim de garantir a qualidade final do produto. Entre os defeitos mais críticos estão: Corrente de desvio (efeito shunt), excessiva indentação, expulsão de material (salpico) que por muitas vezes acabam gerando rebarbas ou até mesmo furos nas chapas, ponto solto, lentilha pequena e descontinuidade interna (falha no ponto). Alguns exemplos destes defeitos são mostrados na Figura 44 .
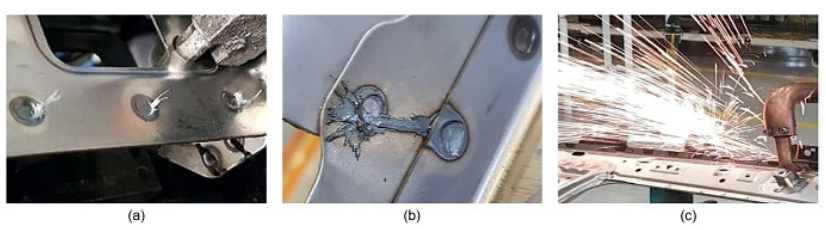

Figura 4. (a) Rebarba na superfície, (b) rebarba na interface e (c) salpico. Fonte: Dos autores

\section{DIÂMETROS DO ELETRODO}

Segundo Emílio Wainer, para determinar o diâmetro dos eletrodos para soldagem de chapas com a mesma espessura, em que o calor gerado em ambas as peças deva ser igual, considera-se que as faces de contato dos eletrodos com a peça seja aproximadamente $1,6 \mathrm{~mm}$ maior que o diâmetro do ponto de solda, conforme a Equação 3:

$$
D=5 \cdot S 1 / 2
$$

Em que: $D=$ Diâmetro do ponto $(\mathrm{mm}) ; S=$ Espessura da chapa $(\mathrm{mm})$.

Já para soldagem de peças com espessuras diferentes ou materiais dissimilares são necessários diâmetros diferentes para adequar a geração de calor na região a ser soldada. No caso de espessuras diferentes, o eletrodo com menor diâmetro deve ser colocado em contato com a peça de menor espessura. Para peças dissimilares, apresentam condutibilidades diferentes, mas com mesma espessura o 
eletrodo de menor diâmetro deverá ficar com a peça que apresentar maior condutibilidade, podendo ser calculada a área de contato, conforme a Equação $4^{3}$ :

$$
G 1 A 1 / e 1_{=} G 2 A 2 / e 2_{=} G n A n / e n
$$

Em que: $G 1, G 2 \ldots=$ Condutibilidade elétrica das peças; $A 1, A 2 \ldots=$ Área de contato dos eletrodos; $e 1, e 2 \ldots=$ Espessura das peças.

A Figura 5 apresenta um comparativo de possíveis variações do diâmetro dos eletrodos em função da condutibilidade específica da peça que está sendo soldada.

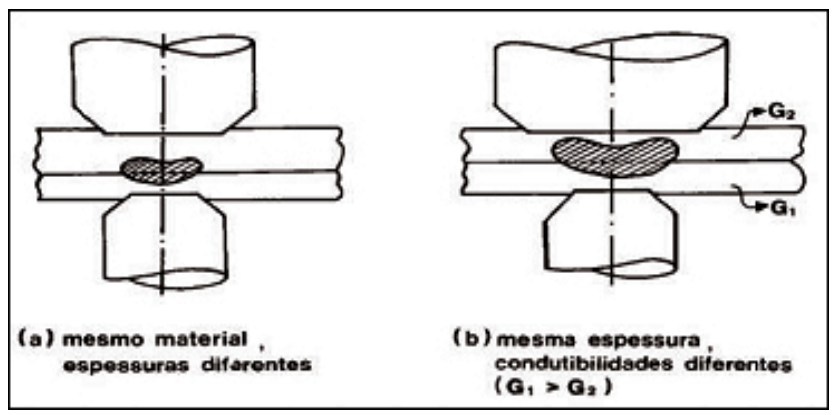

Figura 5: Diâmetro do eletrodo em função da soldagem de metais de espessura ou condutibilidade diferentes. Fonte: referência [7].

\section{INSPEÇÕES}

Durante o processo de fabricação utilizando a soldagem a ponto por resistência, podem ser utilizados alguns métodos para validação da qualidade da lentilha da solda, sendo ensaios de natureza destrutiva e não destrutivas. Dentre os ensaios não destrutivos temos, as inspeções visuais e ultrassonografia que geralmente são realizadas na peça pronta validando a solda realizada. Já nos ensaios destrutivos, temos: teste de tração, arrancamento, destacamento, tensão cisalhante, torção e ensaios metalográficos (macrografia e micrografia).

\section{Metodologia}

O presente trabalho foi dividido em duas partes, em ambas foram feitas as soldagens e análise de 80 corpos de prova de aço carbono, sendo que na primeira parte os corpos de prova eram compostos por duas chapas com espessura de $0,8 \mathrm{~mm}$, na segunda parte eram formados por três chapas sendo duas de $0,8 \mathrm{~mm}$ e uma de $0,6 \mathrm{~mm}$.

As duas partes foram divididas em três etapas cada, ocorrendo a soldagem dos corpos de prova com variação dos parâmetros no qual a corrente, força ou tempo tiveram seus valores alterados, sendo que dois dos três foram mantidos constantes e um sofreu alterações. Deste modo os corpos foram submetidos a ensaios de tração, para que a força máxima suportada pelo ponto de solda e o diâmetro da lentilha após o arrancamento pudessem ser analisados e assim determinar o parâmetro ideal para dar sequência as próximas etapas como mostrado no fluxograma, apresentado na Figura 6:

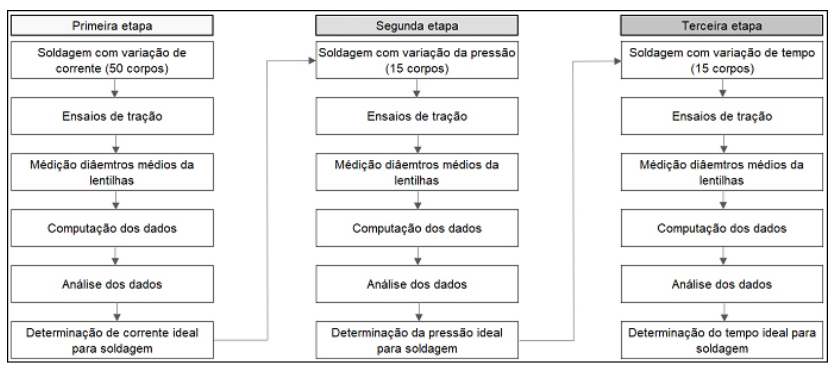

Figura 6: Fluxograma das etapas de soldagem. Fonte: Dos autores.

Pelo fato de a corrente ser o parâmetro mais influente na geração de calor na junta soldada, como mostrado pela Equação 1, foram utilizados um maior número de corpos de prova para a determinação de seu valor otimizado, possibilitando ensaios com um maior range de alteração, permitindo o melhor acompanhamento das suas influências na resistência mecânica da solda e na curva de soldabilidade. A Tabela 1 apresenta os parâmetros de soldagem de ambas às partes. 
Tabela 1: Parâmetros da soldagem. Fonte: Dos Autores

\begin{tabular}{|c|c|c|c|c|c|c|c|c|c|c|c|c|c|c|c|c|c|c|c|c|c|}
\hline & Corrente(kA) & 6,0 & 6,5 & 7,0 & 7,5 & 8,0 & 8,5 & 9,0 & 9,5 & 10,0 & 10,5 & 8,5 & 8,5 & 8,5 & 8,5 & 8,5 & 8,5 & 8,5 & 8,5 & 8,5 & 8,5 \\
\hline & Tempo(ms) & 310 & 310 & 310 & 310 & 310 & 310 & 310 & 310 & 310 & 310 & 310 & 310 & 310 & 310 & 310 & 150 & 200 & 250 & 300 & 350 \\
\hline & Força(kN) & 2,6 & 2,6 & 2,6 & 2,6 & 2,6 & 2,6 & 2,6 & 2,6 & 2,6 & 2,6 & 2,2 & 2,6 & 3 & 3,4 & 3,8 & 2,5 & 2,5 & 2,5 & 2,5 & 2,5 \\
\hline & Corrente(kA) & 6,0 & 6,5 & 7,0 & 7,5 & 8,0 & 8,5 & 9,0 & 9,5 & 10,0 & 10,5 & 8,0 & 8,0 & 8,0 & 8,0 & 8,0 & 8,0 & 8,0 & 8,0 & 8,0 & 8,0 \\
\hline & Tempo(ms) & 250 & 250 & 250 & 250 & 250 & 250 & 250 & 250 & 250 & 250 & 250 & 250 & 250 & 250 & 250 & 150 & 200 & 250 & 300 & 350 \\
\hline$U^{U}$ & Força(kN) & 2,2 & 2,2 & 2,2 & 2,2 & 2,2 & 2,2 & 2,2 & 2,2 & 2,2 & 2,2 & 1,6 & 1.9 & 2,2 & 2,5 & 2,8 & 2,5 & 2,5 & 2,5 & 2,5 & 2,5 \\
\hline & $\begin{array}{c}\mathbb{N}^{\circ} \text { Corpos de } \\
\text { prova }\end{array}$ & 5 & 5 & 5 & 5 & 5 & 5 & 5 & 5 & 5 & 5 & 3 & 3 & 3 & 3 & 3 & 3 & 3 & 3 & 3 & 3 \\
\hline
\end{tabular}

\section{PREPARAÇÃO DOS CORPOS DE PROVA}

Os corpos de prova foram feitos com peças de montagem das carrocerias, cortadas seguindo as dimensões impostas pela norma EN-ISO 14273. Finalizado os cortes dos corpos de prova, esses foram conformados e tiveram suas extremidades lixadas para garantir um bom assentamento das chapas quando sobrepostas, reduzindo o gap entre elas. Na Figura 7 é possível verificar as dimensões dos corpos de prova, em milímetros, impostas pela norma para o mix utilizados em ambas partes do projeto.

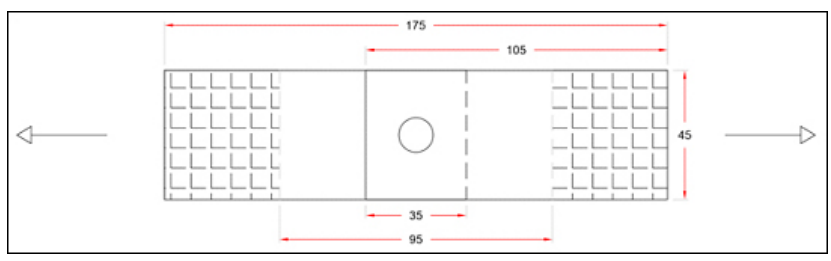

Figura 7: Dimensão dos corpos de prova. Fonte: Dos autores.

\section{SOLDAGEM DOS CORPOS DE PROVA}

Realizou-se o processo de soldagem nos corpos de prova, através da RSW (solda a ponto) com a utilização de uma máquina manual e pinça do tipo $\mathrm{C}$, comando de solda com $1000 \mathrm{hz}$ (média frequência) sendo o controlador de solda da Bosch. No programa BOS6000 foi feita a parametrização e acompanhamento das curvas de soldagem durante o processo. Para assegurar a correta parametrização foi realizada a calibração da ponteadeira com o auxílio do Weld tester Myachi M380A, para que os valores solicitados pelo programa fossem os encontrados na saída do circuito secundário garantindo a soldagem. Outro equipamento utilizado como auxílio na soldagem foi uma morsa na qual os mix foram presos evitando a fuga de corrente, acidentes e mal sobreposição dos corpos de prova.

O eletrodo utilizado na soldagem possui liga de $\mathrm{CuCrZr}$ com condutibilidade de 77 e dureza de $80 \mathrm{Hrb}$, foi condicionado no decorrer da soldagem dos corpos de prova com a ajuda de um dressador manual, garantindo seu dimensional durante todo o processo de soldagem, checado com um gabarito de $6 \mathrm{~mm}$ de diâmetro efetuando essa usinagem a cada 10 pontos, conforme a Figura 8 .
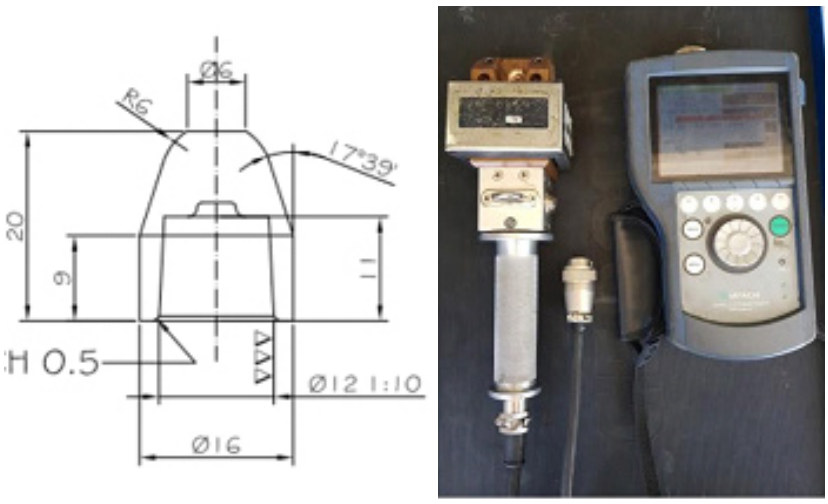

Figura 8: Dimensões do eletrodo e Weld Tester. Fonte: Dos autores.

\section{ENSAIOS DE TRAÇÃO}

Os ensaios de resistência à tração foram realizados em uma máquina modelo Instron com célula de carga com capacidade de $30 \mathrm{kN}$. Os ensaios foram utilizados para avaliar as propriedades mecânicas e resistência à tração dos corpos de prova soldados onde a velocidade de deslocamento do ensaio foi de $10 \mathrm{~mm} /$ minuto para os dois mix. Na Figura 9, é mostrado a máquina de tração que foi utilizada neste trabalho. 

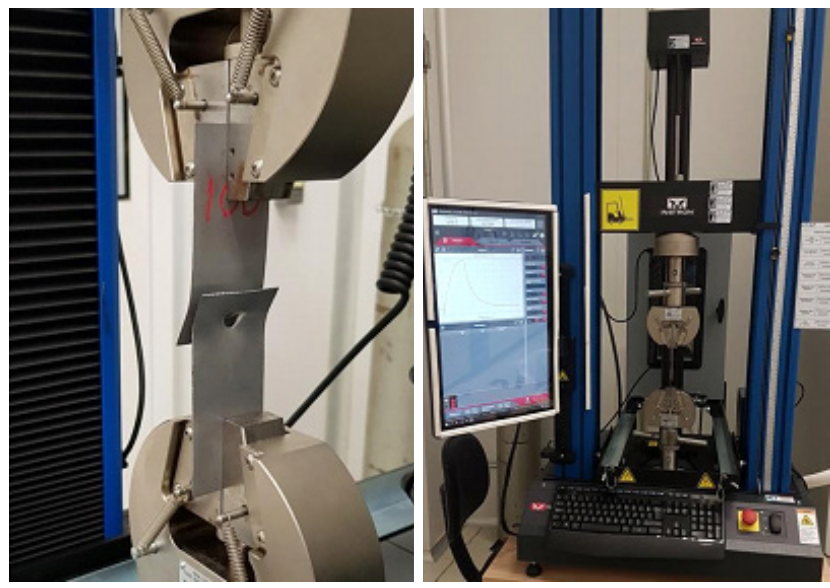

Figura 9: Tracionadora Instron. Fonte: Dos autores

\section{Resultados e Discussão}

\section{SOLDAGEM DE 2 CHAPAS}

Os resultados de força máxima e diâmetro das lentilhas obtido com ensaios de tração na primeira etapa estão apresentados na Tabela 2 .

Tabela 2: Forças máximas e diâmetro médio dos pontos pela variação da corrente. Fonte: Dos Autores

\begin{tabular}{|c|c|c|c|c|c|c|c|c|c|c|}
\hline \multirow{2}{*}{$\begin{array}{c}\text { Corrente } \\
\text { (kA) }\end{array}$} & \multicolumn{2}{|c|}{1} & \multicolumn{2}{|c|}{2} & \multicolumn{2}{|c|}{3} & \multicolumn{2}{|c|}{4} & \multicolumn{2}{|c|}{5} \\
\hline & $\begin{array}{l}\text { F.Máx } \\
\text { (N) }\end{array}$ & $\begin{array}{c}\text { D.Médio } \\
(\mathrm{mm})\end{array}$ & $\begin{array}{l}\text { F.Maxx } \\
\text { (N) }\end{array}$ & $\begin{array}{c}\text { D. Médio } \\
(\mathrm{mm})\end{array}$ & $\begin{array}{l}\text { F.Máx } \\
\text { (N) }\end{array}$ & $\begin{array}{c}\text { D.Médio } \\
(\mathrm{mm})\end{array}$ & $\begin{array}{l}\text { F.Máx } \\
\text { (N) }\end{array}$ & $\begin{array}{c}\text { D.Médio } \\
\text { (mm })\end{array}$ & $\begin{array}{l}\text { F.Máx } \\
\text { (N) }\end{array}$ & $\begin{array}{c}\text { D. Médio } \\
(\mathrm{mm})\end{array}$ \\
\hline 6,0 & 2904 & 3,5 & 3305 & 3,5 & 3444 & 3,2 & 2904 & 3,7 & 3496 & 3,8 \\
\hline 6.5 & 3181 & 4,0 & 3555 & 4,4 & 3257 & 4,4 & 3145 & 4,3 & 3542 & 4,3 \\
\hline 7,0 & 3501 & 4,5 & 3995 & 4,5 & 3628 & 4,7 & 3989 & 5,0 & 3925 & 4,9 \\
\hline 7,5 & 4183 & 5,2 & 3720 & 4,9 & 4114 & 5,1 & 4027 & 5,5 & 3904 & 5,2 \\
\hline 8,0 & 4288 & 5,7 & 4055 & 5,4 & 4236 & 5,8 & 4139 & 5,4 & 4229 & 5,6 \\
\hline 8,5 & 4315 & 6,0 & 4202 & 5,5 & 4111 & 5,3 & 4332 & 5,9 & 3994 & 5,7 \\
\hline 9,0 & 3770 & 4,5 & 4716 & 5,3 & 3533 & 3,4 & 4499 & 5,9 & 4552 & 6,3 \\
\hline 9,5 & 4611 & 6,0 & 4760 & 6,4 & 3580 & 3,7 & 4118 & 4,6 & 3907 & 5,3 \\
\hline 10,0 & 4644 & 6,1 & 4509 & 6,7 & 4518 & 5,2 & 4276 & 4,4 & 4687 & 6,2 \\
\hline 10,5 & 4863 & 6,8 & 4596 & 6,1 & 4842 & 6,7 & 4523 & 5,6 & 4614 & 5,7 \\
\hline
\end{tabular}

Com as médias dos valores da Tabela 2, foi possível a elaboração de um gráfico de soldabilidade do mix proposto para melhor análise dos resultados com as correntes de soldagem, como mostrado no Gráfico 1.

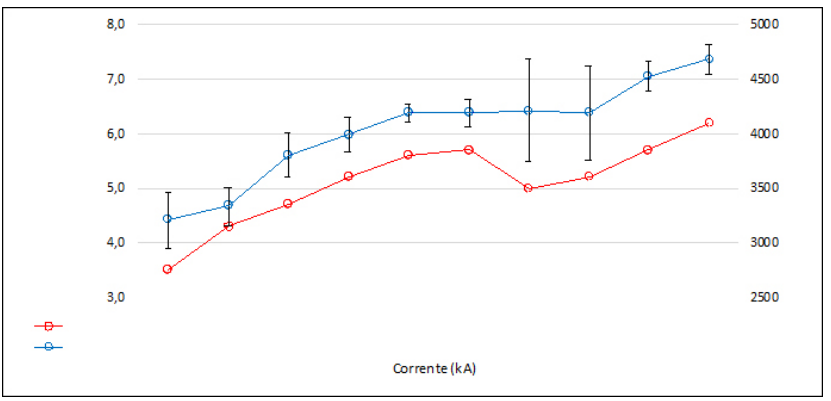

Gráfico 1: Relação de força máxima e diâmetro do ponto com variação de corrente. Fonte: Dos Autores

Analisando o Gráfico 1, observa-se uma tendência de aumento tanto da força máxima quanto no diâmetro do ponto de solda de acordo com o aumento da corrente. Segundo ${ }^{10,11}$, o diâmetro da lentilha influência na resistência da junta soldada no ensaio de tração e cisalhamento, aumentado sua resistência mecânica com o aumento do diâmetro. Foi observada durante a soldagem com $8,5 \mathrm{kA}$ a ocorrência de um salpico, enquanto que nas correntes subsequentes na grande maioria dos pontos, foi evidenciado a expulsão de material, gerando rebarbas intersticiais. Desta forma, a presença do salpico pode ter influenciado na redução do diâmetro médio e no aumento do desvio padrão das forças máximas resistidas.

De acordo com a norma EN-ISO 14273, o diâmetro mínimo para o mix soldado é de $4,48 \mathrm{~mm}$ valor este que somente foi obtido nas soldagens com correntes acima de $7 \mathrm{kA}$. Segundo ${ }^{12}$ a máxima corrente corresponde ao início da expulsão de material na junta soldada e o mínimo se vê determinada ao diâmetro imposto pelas normas, sendo assim, a região de soldabilidade foi limitada para valores de corrente entre 7 a 8,0 kA. Levando-se em consideração também a alta resistência e diâmetro apresentado atrelado a um baixo desvio padrão, a partir da análise desses critérios a corrente de $8 \mathrm{kA}$ foi a mais adequada para realização das etapas subsequentes.

Os resultados de força máxima e diâmetro das lentilhas obtidos através dos ensaios de tração da segunda etapa estão apresentados na Tabela 3. 
Tabela 3: Forças máximas e Diâmetro médio dos pontos pela variação da força. Fonte: Dos Autores

\begin{tabular}{ccccccc}
\hline \multirow{2}{*}{ Força $(\mathrm{kN})$} & \multicolumn{2}{c}{1} & \multicolumn{2}{c}{2} & \multicolumn{2}{c}{3} \\
\cline { 2 - 7 } & F. Máx(N) & D. Médio(mm) & F. Máx(N) & D. Médio(mm) & F. Máx(N) & D. Médio(mm) \\
\hline 1,6 & 3420 & 3,5 & 3737 & 4,4 & 3789 & 4,1 \\
\hline 1,9 & 3736 & 4,0 & 4229 & 5,9 & 3825 & 4,2 \\
\hline 2,2 & 4220 & 4,5 & 3549 & 5,4 & 4212 & 5,8 \\
\hline 2,5 & 4283 & 6,1 & 4206 & 5,8 & 4257 & 5,7 \\
\hline 2,8 & 3992 & 5,1 & 4046 & 4,9 & 4398 & 5,4 \\
\hline
\end{tabular}

Com as médias dos valores da Tabela 3, foi possível a elaboração de um gráfico de curva da soldabilidade do mix proposto para melhor análise dos resultados das forças de soldagem, como mostrado no Gráfico 2.

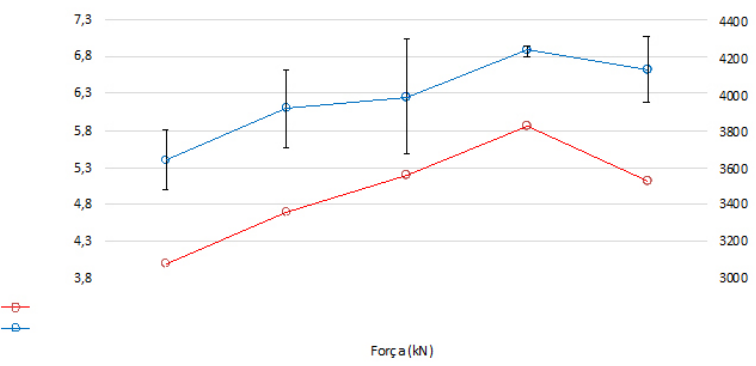

Gráfico 2: Relação de força máxima e diâmetro do ponto com variação de pressão. Fonte: Dos Autores

No Gráfico 2 também pode-se observar um aumento dos valores de força e diâmetro do ponto de solda de 1,6 a $2,5 \mathrm{kN}$, comum a leve redução em $2,8 \mathrm{kN}$, diferenciando-se da curva de corrente por apresentar as expulsões de material no início do diagrama de soldabilidade, comos valores de 1,6 e 1,9kN. Sendo assim, a curva de soldagem foi limitada entre $2,2 \mathrm{kN}$ a $2,8 \mathrm{kN}$, que por sua vez foi selecionada a força de $2,5 \mathrm{kN}$ devido à maior resistência, diâmetro médios e menor desvio padrão dos demais valores ensaiados.

Os resultados de força máxima e diâmetro das lentilhas obtidos através dos ensaios de tração da terceira etapa estão apresentados na Tabela 4.
Tabela 4: Forças máximas e Diâmetro médio dos pontos pela variação do tempo. Fonte: Dos Autores

\begin{tabular}{ccccccc}
\hline \multirow{2}{*}{ Tempo(ms) } & \multicolumn{2}{c}{1} & \multicolumn{2}{c}{2} & \multicolumn{2}{c}{3} \\
\cline { 2 - 7 } & F. Máx(N) & D. Médio(mm) & F. Máx(N) & D. Médio(mm) & F. Máx(N) & D. Médio(mm) \\
\hline 150 & 4038 & 5,2 & 4052 & 5,2 & 4011 & 5,2 \\
\hline 200 & 3554 & 4,5 & 3781 & 4,4 & 3752 & 4,5 \\
\hline 250 & 4224 & 5,4 & 4236 & 5,7 & 4171 & 5,4 \\
\hline 300 & 4293 & 5,5 & 4248 & 5,5 & 3906 & 4,7 \\
\hline 350 & 4238 & 5,6 & 4252 & 5,2 & 4103 & 5,5 \\
\hline
\end{tabular}

Com as médias dos valores da Tabela 4, foi possível a elaboração de um gráfico de curva da soldabilidade do mix proposto para melhor análise dos resultados dos ensaios, como mostrado no Gráfico 3.

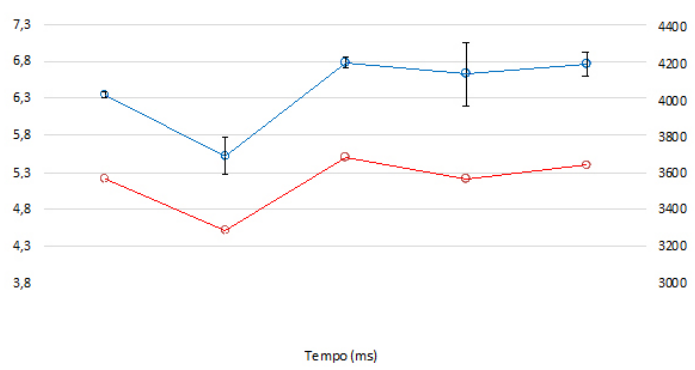

Gráfico 3: Relação de força máxima e diâmetro do ponto com variação de tempo. Fonte: Dos Autores

Por meio do Gráfico 3 pode-se observar que o tempo de soldagem, dentre os três parâmetros, apresentou menor influência nos valores obtidos nos ensaios de tração, apresentando nas 5 faixas de ensaios diâmetros satisfatórios. Fato que pode ter sido decorrente da correta parametrização da corrente e força de soldagem, tornando a soldagem mais estável. De acordo $\mathrm{com}^{13}$, foi observado que a zona fundida aumenta com o aumento do tempo, chegando a um limite em que após isso, a zona fundida reduz de tamanho, devido à passagem de calor para as zonas vizinhas do ponto de solda fato que não se teve presente no trabalho pelos baixos valores de tempo ensaiados. Assim com força máxima e diâmetro da lentilha da solda superiores aos demais tempos de soldagem atrelado a uma constância dos dados obtidos foi atribuído o tempo de $250 \mathrm{~ms}$ para a execução do ponto otimizado. 
Deste modo, os 3 parâmetros bases otimizados para a soldagem de duas chapas de $0,8 \mathrm{~mm}$ ficam sendo: corrente de soldagem de $8 \mathrm{kA}$, força dos eletrodos de $2,5 \mathrm{kN}$ e tempo de soldagem de $250 \mathrm{~ms}$. Tendo o ponto otimizado uma média de força máxima de $4211 \mathrm{~N}$ e um diâmetro de 5,5mm.

\section{SOLDAGEM 3 CHAPAS}

Os resultados de força máxima e diâmetro das lentilhas obtidos através dos ensaios de tração da primeira etapa na soldagem com três chapas estão apresentados na Tabela 5 .

Tabela 5: Forças máximas e diâmetro médio dos pontos pela variação da corrente. Fonte: Dos Autores

\begin{tabular}{ccccccccccc}
\hline $\begin{array}{c}\text { Corrent } \\
\mathrm{e}(\mathrm{kA})\end{array}$ & \multicolumn{3}{c}{1} & \multicolumn{2}{c}{2} & \multicolumn{2}{c}{3} & & 4 & \multicolumn{2}{c}{5} \\
\hline 6,0 & 2830 & 3,8 & 680 & 0,0 & 2454 & 3,8 & 2778 & 4,1 & 2767 & 4,0 \\
\hline 6,5 & 3157 & 4,8 & 3388 & 4,8 & 3233 & 5,3 & 3455 & 5,0 & 3343 & 5,0 \\
\hline 7,0 & 3250 & 5,5 & 3216 & 5,0 & 2962 & 5,0 & 3405 & 5,4 & 2866 & 4,8 \\
\hline 7,5 & 3078 & 5,5 & 2978 & 5,3 & 3336 & 6,1 & 3017 & 5,1 & 2953 & 4,9 \\
\hline 8,0 & 3767 & 5,2 & 3264 & 5,3 & 3212 & 5,3 & 3193 & 5,0 & 3042 & 5,2 \\
\hline 8,5 & 3273 & 5,6 & 3222 & 5,8 & 3085 & 5,6 & 3250 & 5,0 & 3292 & 5,7 \\
\hline 9,0 & 3737 & 6,2 & 3254 & 5,9 & 3228 & 6,2 & 3133 & 5,7 & 3259 & 5,6 \\
\hline 9,5 & 3225 & 5,8 & 3336 & 5,9 & 3254 & 5,5 & 3339 & 5,2 & 3313 & 6,0 \\
\hline 10,0 & 3550 & 5,6 & 3213 & 5,9 & 3307 & 6,1 & 3395 & 6,4 & 3487 & 6,3 \\
\hline 10,5 & 3703 & 7,1 & 3820 & 6,8 & 3623 & 6,6 & 3426 & 6,4 & 4411 & 6,6 \\
\hline & & & & & & & & & & \\
\hline
\end{tabular}

A partir da média dos valores apresentados na Tabela 5 foi possível realizar um gráfico da curva de soldabilidade para uma melhor visualização da corrente a ser utilizada para o mix, conforme apresentado no Gráfico 4.

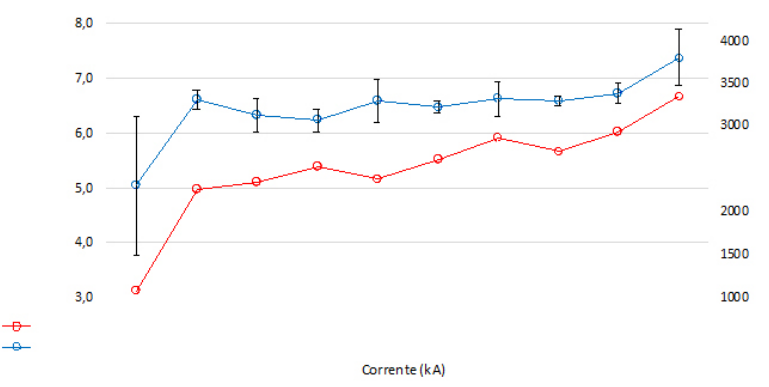

Gráfico 4: Relação de força máxima e diâmetro do ponto com variação de corrente. Fonte: Dos Autores
Durante a soldagem dos corpos de prova a presença de salpicos se deu em toda a faixa de corrente percorrida, criando certa instabilidade nos valores coletados de força máxima suportada e diâmetro da lentilha da solda, fato bastante perceptível através da análise do Gráfico 4 . Levando-se em consideração que fora adotado um tempo de pré-pressão de $1000 \mathrm{~ms}$, que se mostrou suficiente, por meio da análise com o Weld tester, para a estabilização da pressão exercida pelas pinças, leva a crer que a expulsão de material foi provocada pela baixa força utilizada na soldagem, em que os 2,6 kN adotados não foram suficientes para um correto assentamento entre as 3 chapas.

Devido à instabilidade apresentada pelos resultados, foram feitos novos ensaio utilizando 3 correntes que se destacaram, sendo elas 8,5; 9,0 e 9,5kA, pelo baixo desvio padrão, força e diâmetro do ponto satisfatório nesta faixa. Portanto através de arrancamentos manuais e medição do diâmetro de soldagem foi determinado que a corrente de 8,5kA apresentava valores mais constantes de diâmetro.

Dando sequência aos ensaios com a corrente previamente determinada de $8,5 \mathrm{kA}$ foi realizada a segunda etapa para determinação da pressão de soldagem, os valores obtidos estão na Tabela 6 .

Tabela 6: Forças máximas e Diâmetro médio dos pontos pela variação da força. Fonte: Dos Autores

\begin{tabular}{ccccccc}
\hline & \multicolumn{2}{c}{1} & \multicolumn{3}{c}{2} \\
Pressão (kN) & F. Max & D. Medio & F. Max & D. Médio & F. Máx & D. Médio \\
\hline 1,6 & 3233,6 & 5,20 & 3357 & 5,35 & 3331 & 5,45 \\
\hline 1,9 & 3178,8 & 5,40 & 3275 & 5,40 & 3749 & 5,60 \\
\hline 2,2 & 3564,0 & 5,40 & 3704 & 5,75 & 3825 & 5,60 \\
\hline 2,5 & 3470,6 & 5,70 & 3650 & 5,80 & 3495 & 5,60 \\
\hline 2,8 & 3315,4 & 5,10 & 3720 & 5,70 & 3762 & 5,70 \\
\hline
\end{tabular}

A partir da média dos valores apresentados na Tabela 6 foi possível realizar um gráfico da curva de soldabilidade do mix proposto para melhor análise dos resultados das forças de soldagem, como mostrado no Gráfico 5. 


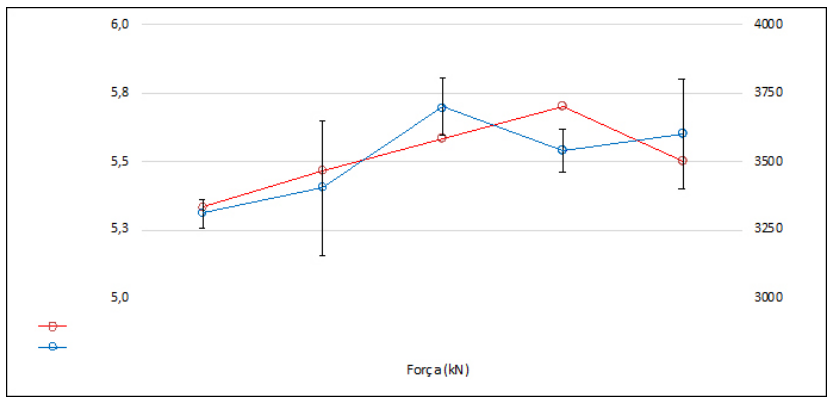

Gráfico 5: Relação de força máxima e diâmetro do ponto com variação de pressão. Fonte: Dos Autores

Como o esperado a soldagem com pressão de 2,2 e 2,6 $\mathrm{kN}$ apresentou expulsões de material, consequentemente diâmetros da lentilha e força máximas suportadas inferiores as demais forças ensaiadas, assim limitando a soldagem para valores de 3 a 3,8 $\mathrm{kN}^{1}$. Observou em seu estudo que os diâmetros das lentilhas de solda tendem a ser menores com a redução da pressão de soldagem.

Deste modo, considerando diferença de apenas em $0,1 \mathrm{~mm}$ e $159 \mathrm{~N}$ entre a pressão de 3,0 e $3,4 \mathrm{kN}$, foi determinado que a etapa subsequente fosse realizada com $3 \mathrm{kN}$ buscando minimizar a indentação ocorrida no ponto de solda, alinhando aos interesses de indústrias automobilísticas, onde muito é presado pela qualidade superficial dos pontos de solda sem alteração significante na qualidade da soldagem.

Os dados de forças máximas e diâmetro médio dos pontos pela variação do tempo da terceira etapa estão apresentados na Tabela 7 .

Tabela 7: Forças máximas e Diâmetro médio dos pontos pela variação do tempo. Fonte: Dos Autores

\begin{tabular}{ccccccc}
\hline & \multicolumn{2}{c}{1} & \multicolumn{2}{c}{2} & \multicolumn{2}{c}{3} \\
\cline { 2 - 7 } Tempo (ms) & F. Máx & D. Médio & F. Máx & D. Médio & F. Máx & D. Médio \\
\hline 150 & 3359,2 & 5,40 & 3432 & 5,75 & 3749 & 5,75 \\
\hline 200 & 3924,1 & 6,05 & 3707 & 5,85 & 4074 & 5,90 \\
\hline 250 & 3865,7 & 5,65 & 3842 & 5,90 & 3753 & 6,25 \\
\hline 300 & 3841,7 & 6,10 & 4229 & 6,20 & 3904 & 6,10 \\
\hline 350 & 3950,2 & 6,60 & 4097 & 6,25 & 4038 & 6,70 \\
\hline
\end{tabular}

Com as médias dos valores da Tabela 7 , foi possível a elaboração de um gráfico de curva da soldabilidade do mix proposto para melhor análise dos resultados dos ensaios, como mostrado no Gráfico 6.

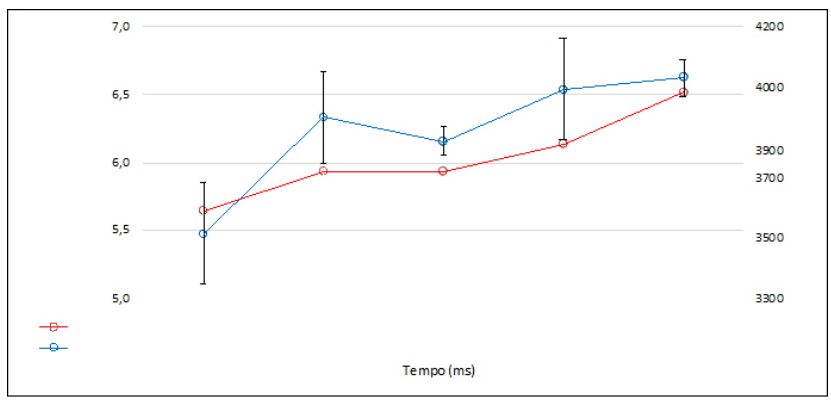

Gráfico 6: Relação de força máxima e diâmetro do ponto com variação de tempo. Fonte: Dos Autores

$\mathrm{Na}$ terceira etapa foi possível verificar que assim como na soldagem de 2 chapas, o tempo também foi o parâmetro que menos impactou na soldagem, apresentando poucas variações do diâmetro dos pontos e a forças máximas suportadas. Segundo ${ }^{3,14}$ as soldas realizadas com um menor tempo apresentam melhores rendimentos térmicos sendo o valor total das perdas de calor proporcional a raiz quadrada do tempo de soldagem. Assim fazendo com que a determinação do parâmetro otimizado leve em consideração não somente suas propriedades mecânicas como também sua velocidade de produção e rendimento térmico, tendo em vista a alta demanda esperada.

Deste modo apresentando valores de força máxima e diâmetros satisfatórios o tempo de $250 \mathrm{~ms}$ foi determinado como sendo o mais eficiente para a soldagem em questão. De modo que fiquem sendo os parâmetros otimizados para a soldagem do mix de 3 chapas, corrente de soldagem de $8,5 \mathrm{kA}$; Força de $3,0 \mathrm{kN}$ e um tempo de $250 \mathrm{~ms}$.

\section{Conclusão}

O presente estudo, que teve como objetivo a obtenção de parâmetros de soldagem otimizados para os 2 mix de chapas 
propostos, com base nos resultados obtidos revelou-se que:

- Durante os ensaios foi observado que a força máxima suportada pela junta soldada e diâmetro médio das lentilhas apresentaram correlação em função da corrente e tempo de soldagem, com os maiores valores obtidos nos finais das faixas de soldabilidade.

- Dentro dos corpos de prova avaliados foi notada uma tendência de aumento dos desvios padrões quando evidenciada a expulsão de material durante o processo de soldagem, muitas vezes não significando redução do diâmetro da lentilha, mas com uma menor variação da força máxima suportada.

- Nota-se que a soldagem com valores adequados para corrente e pressão apresentaram propriedades mecânicas satisfatórias e baixa variação dos diâmetros das lentilhas em toda a faixa de soldabilidade dos tempos ensaiados, tornando possível a determinação do seu valor de acordo com a necessidade do processo em questão.

- Os parâmetros otimizados para a soldagem de duas chapas são: corrente de soldagem $8,0 \mathrm{kA}$; pressão de 2,5 $\mathrm{kN}$ e tempo de soldagem de $250 \mathrm{~ms}$.

- Para a soldagem do mix de três chapas os parâmetros encontrados foram: corrente de soldagem 8,5 kA; pressão de $3,0 \mathrm{kN}$ e tempo de soldagem de $250 \mathrm{~ms}$.

\section{Referências}

1. Ruiz, D. C.; Batalha, G. F. Estudo de um critério de modo de falha para solda a ponto por resistência. Escola Politécnica da USP, n. 2, 2005.

2. Kavamura, H. A. Aplicação de Solda Laser em Carrocerias Automotivas: Estudo Comparativo entre a Solda Laser e a Solda Ponto por Resistência. p. 108, 2007.

3. SOLDAGEM - PROCESSOS E METALURGIA (Emílio Wainer, Sérgio Brandi e Fábio Décourt Homem de Mello).pdf. [s.l: s.n.].

4. Paulo, S. Danilo Stocco caracterização de solda por resistência a ponto através deavaliações não destrutivas. 2010.

5. WELINGTON APARECIDO DOS SANTOS Estudo da Influência dos Parâmetros de Regulagem na Soldagem por Resistência na Indústria Automobilística São Caetano do Sul 2013.[s.d.].
6. Aures, J. E. V. ESTUDO DA FORMAÇÃO, GEOMETRIA E RESISTÊNCIADO PONTONA SOLDAGEM POR RESISTÊNCIA: UMA ABORDAGEM ESTATÍSTICA. p. 164, 2006.

7. Batista, M. Estudo comparativo da soldabilidade de chapas para indústria automotiva utilizando dois equipamentos de soldagem a ponto por resistência. 17 Oct. 2011. Universidade de São Paulo. 17 Oct. 2011.

8. Antônio, M.; Junior, P.; Ponto, S. Avaliação das Juntas Soldadas Utilizando o Processo. p. 1-15,[s.d.].

9. Jong, Y.-S. et al. Microstructural Evolution and Mechanical Properties of Resistance Spot Welded Ultra High Strength Steel Containing Boron. Materials Transactions, v. 52, n. 6, p. 1330-1333, 2011.

10. Jong, Y. S. et al. Microstructural evolution and mechanical properties of resistance spot welded ultra high strength steel containing boron. Materials Transactions.Anais... 2011.

11. Pouranvari, M. Susceptibility to interfacial failure mode in similar and dissimilar resistance spot welds of DP600 dual phase steel and low carbon steel during cross-tension and tensile-shear loading conditions. Materials Science and Engineering: A, v. 546, p. 129-138, Jun. 2012.

12. Resistance Welding. [s.1.] CRC Press, 2005.

13. Penteado, K. M. Otimização da Solda de Pontos por Resistência Elétrica na Liga de Alumínio 5052-H32 através do Projeto e Análise de Experimentos (DOE). p. 93, 2011.

14. Machado, I. G. Soldagem \& Técnicas Conexas: Processos. [s.l:s.n.].

\section{Kennedy R. Rosario*, João C. R. Costa, Sérgio M. Brandão, Márcio J. Dias, Rosemberg F. N. Rodrigues \& Wilson P. Silva}

Centro Universitário de Anápolis - UniEVANGÉLICA. Avenida Universitária, km 3,5, Centro Universitário, Anápolis, Goiás, Brasil.

*E-mail: kennedyreis97@gmail.com 